OSEANOLOGI DAN LIMNOLOGI DI INDONESIA

Online ISSN: 2477-328X

Akreditasi RISTEKDIKTI No. 21/E/KPT/2018

http://oldi.lipi.go.id

\title{
Pertumbuhan dan Sintasan Juvenil Teripang Pasir Holothuria scabra pada Pemeliharaan Dengan dan Tanpa Rumput Laut Gracilaria sp., Menggunakan Keramba Apung dan Tancap di Tambak
}

\author{
Dedy Kurnianto $^{2}$, Lisa F Indriana ${ }^{1 *}$, Abdul Wahab ${ }^{1}$, Syafriyadi Hafid ${ }^{1}$, Balkam F Badi ${ }^{1}$ \\ ${ }^{1}$ Balai Bio Industri Laut - Lembaga Ilmu Pengetahuan Indonesia \\ Jl. Raya Sengigi, Teluk Kodek, Malaka, Pemenang, Lombok Utara \\ ${ }^{2}$ Pusat Penelitian Oseanografi - Lembaga Ilmu Pengetahuan Indonesia \\ Jl. Pasir Putih 1, Ancol Timur, Jakarta, Indonesia \\ *Email: lisaindriana23@gmail.com
}

Submitted 6 November 2020. Reviewed 18 November 2020. Accepted 4 December 2020.

DOI: 10.14203/oldi.2020.v5i3.340

\begin{abstract}
Abstrak
Teripang pasir dengan nama ilmiah Holothuria scabra telah lama dimanfaatkan dalam industri farmasi, kosmetik, dan pangan. Produksi juvenil teripang pasir merupakan salah satu cara untuk mengatasi masalah ketersediaan bahan baku akibat penurunan populasi teripang di alam.Penelitian ini bertujuan untuk mengetahui pertumbuhan dan sintasan juvenil teripang pasir yang dipelihara bersamaan dengan dan tanpa rumput laut Gracilaria sp., menggunakan keramba apung dan tancap di tambak. Penelitian dilaksanakan pada bulan Mei sampai dengan September 2014. Rancangan percobaan menggunakan Rancangan Acak Lengkap dengan perlakuan pemeliharaan menggunakan keramba jaring apung tanpa rumput laut (ATR), keramba jaring apung dengan rumput laut (ADR), keramba jaring tancap tanpa rumput laut (TTR), dan keramba jaring tancap dengan rumput laut (TDR), masing-masing perlakuan diulang sebanyak 3 kali. Pengamatan pertumbuhan dilakukan setiap 2 minggu. Parameter yang diamati meliputi PertambahanBerat, Laju Pertumbuhan, Laju Pertumbuhan Spesifik, Biomassa, Sintasan, dan Kualitas Air. Hasil penelitian menunjukkan bahwa Rerata PertambahanBerat, Laju Pertumbuhan,dan Laju Pertumbuhan Spesifik menunjukkan hasil yang tidak berbeda nyata antar perlakuan $(\mathrm{P}>0,05)$. Sintasan dan Biomassa menunjukkan perbedaan yang nyata antar perlakuan $(\mathrm{P}<0,05)$. Perlakuan ATR menghasilkan pertambahan berat, laju pertumbuhan spesifik, sintasan, dan biomassa tertinggi, sedang perlakuan TDR menghasilkan pertumbuhan paling rendah. Kualitas perairan selama penelitian berada dalam kisaran optimal untuk pertumbuhan teripang pasir. Penambahan rumput laut Gracilaria sp.menunjukkan pola yang cenderung menghambat pertumbuhan, biomassa, dan sintasan pada pemeliharaan juvenil teripang pasir baik di keramba apung maupun keramba tancap.
\end{abstract}

Kata Kunci : Holothuria scabra, teripang pasir, rumput laut, Gracilaria sp., pertumbuhan, sintasan

\begin{abstract}
Growth and Survival of Sandfish Holothuriascabra Juveniles Grown with and without Seaweed Gracilaria sp., using Floating and Fixed Hapas in Earthen Pond. Holothuriascabra known as sandfish have long been used for pharmaceutical, cosmetic, and food industries. Juveniles production is one of the ways to address the problem of raw material availability due to declining sandfish population in the wild. This research aimed to determine growth performance and survival of sandfish juveniles reared with and without seaweed Gracilaria sp. using floating and fixed hapas in earthen pond. The research was conducted
\end{abstract}




\section{Kurnianto et al.}

from May to September 2014. A completely randomized design was used to arrange 12 hapas of four treatments groups with three replicates including floating hapas without Gracilaria sp. (ATR), floating hapas with Gracilariasp. (ADR), fixed hapas without Gracilaria sp. (TTR) and fixed hapas with Gracilaria sp. (TDR). Some parameters was observed including weight increment, Growth Rate (GR), Specific Growth Rate (SGR), Biomass, Survival, and Water Quality. The result showed that GR and SGR were not significantly different among treatments $(\mathrm{P}>0.05)$. Survival and Biomass showed significant difference among treatments $(\mathrm{P}<0.05)$. ATR has the highest GR, SGR, survival, dan biomass whereas TDR has the lowest GR, SGR, survival, dan biomass. Water quality parameters were in optimal range for sandfish rearing. Added Gracilaria sp.tend to inhibit GR, SGR, survival, dan biomass.

Keywords: Holothuria scabra, sand fish, Gracilaria sp., Growth, Survival.

\section{Pendahuluan}

Teripang Pasir (Holothuria scabra) merupakan salah satu komoditas bernilai ekonomis tinggi (Purcell, 2014). Teripang jenis ini banyak dimanfaatkan sebagai bahan pangan fungsional, obat-obatan, dan kosmetik karena mengandung nutrisi berkualitas tinggi dan senyawa aktif. Tingginya permintaan teripang harus diimbangi dengan produksi agar industrialisasi teripang dapat berjalan dengan baik (Nursid, 2014). Terlebih spesies ini telah masuk dalam red list IUCN karena penangkapan yang berlebih (Hamel, at al., 2013).

Upaya pembenihan teripang di Indonesia telah dimulai sejak tahun 1990an dan berkembang pesat hingga saat ini (Indriana et al., 2017a; Sembiring et al., 1996). Berbagai metode pemeliharaan baik larva maupun juvenil banyak dikembangkan untuk meningkatkan pertumbuhan dan sintasan. Pemilihan metode pemeliharaan juvenil yang tepat sangat diperlukan dalam pembenihan dan pembesaran teripang. Pemeliharaan dapat dilakukan baik di dalam ruangan menggunakan bak pemeliharaan maupun di luar ruangan menggunakan keramba yang dapat diterapkan di tambak maupun laut (Indriana et al., 2017b; Junio-Menez et al., 2017; Purcell et al., 2012). Upaya pemeliharaan juvenil teripang di tambak dapat dilakukan menggunakan keramba dengan metode tancap dan dan metode apung (Firdaus \& Indriana, 2019; Giri et al., 2019; Indriana \& Firdaus, 2020; Padang et al., 2016;).

Permasalahan yang dihadapi dalam produksi atau pembesaran juvenil di tambak diantaranya adalah kurang tepatnya implementasi metode atau sistem pemeliharaan baik secara monokultur, polikultur maupun IMTA (Integrated Multitrophic Aquaculture) (Juinio-Menez et al., 2017; Purcell \& Agudo, 2013; Purcell et al., 2012). Dalam penelitian Firdaus \& Indriana (2019) menyebutkan bahwa pemeliharaan juvenil teripang pasir di tambak mampu menghasilkan pertumbuhan dan sintasan yang tinggi pada awal pemeliharaan namun masih terdapat kendala, salah satunya adalah kematian pada juvenil diakhir pemeliharaan.

Penerapan sistem polikultur teripang pasir dan rumput laut mampu meningkatkan produksi tanpa meningkatkan tekanan terhadap habitat teripang (Namukose et al., 2016). Salah satu rumput laut yang dapat dibudidayakan di tambak adalah Gracilaria sp. (Friedlander \& Levy, 1995). Menurut Firdaus et al. (2016) rumput laut jenis ini dapat menjadi kandidat dalam penerapan budidaya terintegrasi dengan teripang. Penelitian ini bertujuan untuk mengetahui pertumbuhan dan sintasan juvenil teripang pasir $H$. scabra yang dipelihara bersamaan dengan dan tanpa rumput laut Gracilaria sp.pada keramba tancap dan apung di tambak.

\section{Metodologi}

Penelitian dilakukan di tambak Sekotong Lombok Barat, NTB yang merupakan tambak bekas pemeliharaan udang. Penelitian berlangsung dari bulan Mei sampai dengan September 2014. Juvenil teripang pasir yang digunakan merupakan hasil pembenihan di Balai Bio Industri Laut LIPI. Juvenil dipelihara menggunakan keramba $(1 \times 1 \times 1$ $\mathrm{m})$ yang terbuat dari waring bermata jaring $1 \mathrm{~mm}$ menggunakan hapa sistem tancap dan sistem apung (Gambar 1). Rerata berat juvenil pada awal pemeliharaan $0,29 \pm 0,1$ gram dengan kisaran berat $0,19-0,55$ gram dan padat tebar $50 \mathrm{ekor} / \mathrm{m}^{2}$. Rumput laut yang digunakan dalam penelitian ini adalah Gracilaria sp. dengan berat awal pada masing-masing perlakuan sebesar 100 gram. Sirkulasi air terjadi setiap hari mengikuti pasang surut harian air laut. Pakan selama masa pemeliharaan berupa partikel bahan organik dalam air tambak. 

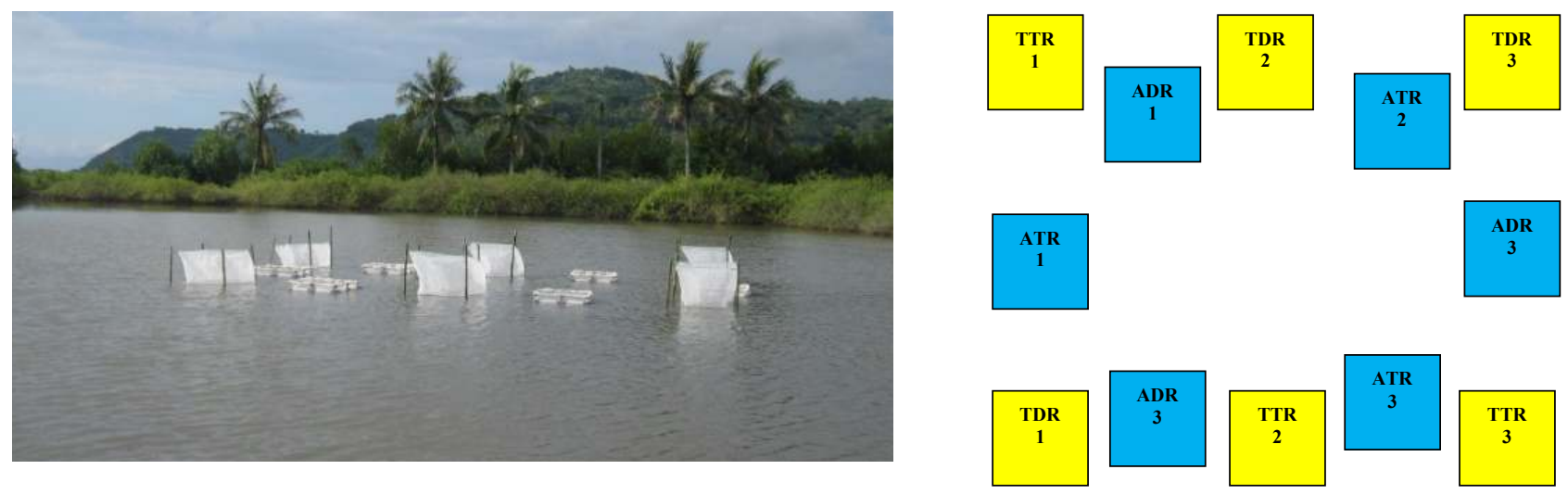

Gambar 1. Lokasi Pemeliharaan Juvenil Holothuria scabra (kiri); denah keramba (kanan).

Figure 1. Location of Holothuria scabra juveniles (left), lay out of hapas (right).

Rancangan penelitian menggunakan Rancangan Acak Lengkap (RAL) dimana masingmasing perlakuan di ulang sebanyak 3 kali.Perlakuan menggunakan wadah pemeliharaan berupa keramba tancap tanpa rumput laut (TTR); keramba tancap dengan rumput laut (TDR); keramba apung tanpa rumput laut (ATR); dan keramba apung dengan rumput laut (ADR).

Pengumpulan data dilakukan setiap 2 minggu selama 4 bulan. Data yang diamati berupa pertambahan berat, biomassa, jumlah juvenil yang hidup, dan kualitas air tambak. Pengamatan pertumbuhan dilakukan dengan menimbang berat juvenil menggunakan timbangan analitik dengan ketelitian 0,01g. Parameter pertumbuhan meliputi pertambahan berat, laju pertumbuhan, laju pertumbuhan spesifik, dan biomassa. Penghitungan jumlah juvenil yang hidup pada awal dan akhir penelitian digunakan untuk mengetahui besarnya sintasan selama pemeliharaan. Parameter kualitas perairan yang diambil meliputi suhu menggunakan termometer raksa, salinitas menggunakan Handrefractometer, $\mathrm{pH}$ dan oksigen terlarut menggunakan Water Quality Cheker. Parameter pertumbuhan dihitung mengikuti Tolon et al. (2017) dan Dumalan et al. (2019):

$$
\begin{gathered}
\text { Pertambahan berat (gram) } \\
\mathrm{W}=\mathrm{Wt}-\mathrm{Wo}
\end{gathered}
$$

Laju Pertumbuhan (gram/hari)

$$
\mathrm{GR}=\frac{\mathrm{Wt}-\mathrm{Wo}}{\mathrm{Tt}-\mathrm{To}}
$$

Laju Pertumbuhan Spesifik (\%/hari)

Biomassa(gram)

$$
\mathrm{SGR}=\frac{\ln (\mathrm{Wt}-\mathrm{Wo})}{\mathrm{Tt}-\mathrm{To}} \times 100 \%
$$

Sintasan $(\%)$

$$
\mathrm{SR}=\frac{\mathrm{Nt}}{\mathrm{No}} \times 100 \%
$$

Dimana $\mathrm{W}=$ rerata pertambahan berat; $\mathrm{GR}=$ Laju Pertumbuhan; SGR = Laju Pertumbuhan Spesifik; $\mathrm{B}=$ biomassa; $\mathrm{SR}=$ Survival Rate (Sintasan); Wt $=$ berat pada waktu $\mathrm{t} ; \mathrm{Wo}=$ berat pada waktu 0 ; $\mathrm{Nt}=$ jumlah teripang yang hidup pada waktu $\mathrm{t}$; No $=$ jumlah teripang awal pemeliharaan.

Data di analisa menggunakan analisis sidik ragam. Analisa dilakukan dengan mengunakan program excel. Apabila terdapat perbedaan rerata antar perlakuan yang nyata maka dilakukan uji lanjut menggunakan uji Duncan (DMRT).

\section{Hasil}

Hasil penelitian menunjukkan bahwa tidak ada beda nyata rerata pertambahan berat antar perlakuan $(\mathrm{P}>0,05)$. Hasil yang sama diperoleh untuk parameter laju pertumbuhan dan laju pertumbuhan spesifik. Kedua parameter menunjukkan hasil tidak berbeda nyata $(\mathrm{P}>0,05)$ antar perlakuan. Tabel 1 menunjukkan bahwa perlakuan ATR menghasilkan pertumbuhan yang tertinggi dengan berat akhir sebesar 17,53 \pm 1,61 gram sedangkan hasil terendah ditunjukkan pada perlakuan TDR sebesar 11,63 $\pm 3,41$ gram. Laju pertumbuhan mencapai nilai tertinggi pada perlakuan ATR dengannilai $0,157 \pm 0,014$ gram/hari dan perlakuan TDR menunjukkan laju pertumbuhan terendah sebesar $0,104 \pm 0,030$ gram/hari. Hasil yang sama juga diperoleh untuk parameter laju pertumbuhan spesifik dan biomassa yaitu perlakuan ATR menunjukkan hasil tertinggi dan TDR memberikan hasil terendah dengan nilai berturut-turut $4,03 \pm 0,38 \%$ dan 3,64 $\pm 0,25 \%$ serta $878,62 \pm 103,27$ gram dan 243,86 $\pm 24,98$ gram. 


\section{Kurnianto et al.}

Tabel 1. Parameter pertumbuhan Holothuria scabra dengan dan tanpa rumput laut Gracilaria sp. di keramba apung dan tancap di tambak.

Table 1. Growth parameters of Holothuria scabra juvenilesreared with and without seaweed Gracilaria sp. in floating and fixed hapa in earthen pond.

$\begin{array}{ccccc}\text { Treatment } & \text { Growth }(\mathrm{g}) & \text { Growth Rate(g/day) } & \text { Specific Growth Rate }(\%) & \text { Biomass }(\mathrm{g}) \\ \text { ATR } & 17.53 \pm 1.61^{\mathrm{a}} & 0.157 \pm 0.014^{\mathrm{a}} & 4.03 \pm 0.38^{\mathrm{a}} & 878.62 \pm 103.27^{\mathrm{c}} \\ \text { ADR } & 12.51 \pm 1.88^{\mathrm{a}} & 0.112 \pm 0.017^{\mathrm{a}} & 3.84 \pm 0.48^{\mathrm{a}} & 559.52 \pm 85.56^{\mathrm{b}} \\ \text { TTR } & 17.02 \pm 4.72^{\mathrm{a}} & 0.152 \pm 0.042^{\mathrm{a}} & 3.77 \pm 0.39^{\mathrm{a}} & 451.19 \pm 64.58^{\mathrm{b}} \\ \text { TDR } & 11.63 \pm 3.41^{\mathrm{a}} & 0.104 \pm 0.030^{\mathrm{a}} & 3.64 \pm 0.25^{\mathrm{a}} & 243.86 \pm 24.98^{\mathrm{a}}\end{array}$

*Rerata yang diikuti huruf yang sama menunjukkan tidak ada beda nyata antara kedua perlakuan $(\mathrm{P}>0,05)$; keterangan ATR (Keramba apung Tanpa Rumput laut) ADR (Keramba Apung dengan Rumput laut) TTR (Keramba Tancap Tanpa Rumput Laut) TDR (Keramba Tancap dengan Rumput laut).

Mean values followed by similar code showed insignificant difference among treatments $(\mathrm{P}>0.05)$; ATR (Floating hapa without seaweed), ADR (Hapa with seaweed), TTR (Fixed hapa without seaweed), TDR (Hapa with seaweed).

Rerata pertumbuhan juvenil teripang pasir yang dipelihara dengan rumput laut pada kurungan tancap maupun apung tidak memiliki pengaruh yang nyata $(\mathrm{P}>0,05)$ (Tabel 1). Pola pertumbuhan juvenil menunjukkan pemeliharaan juvenil bersamaan dengan Gracilaria sp. memiliki nilai rerata pertambahan berat yang lebih kecil dibandingkan dengan perlakuan tanpa penambahan rumput laut (Gambar 2).

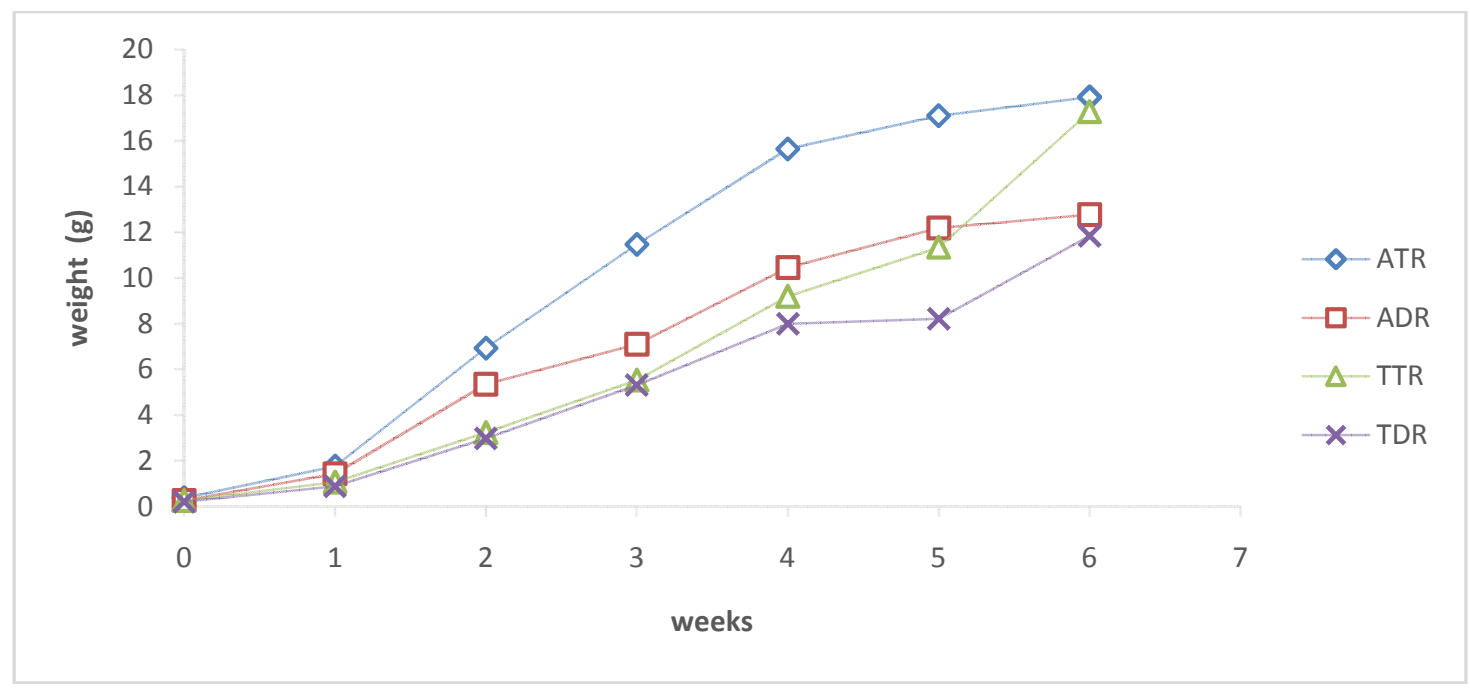

Gambar 2. Pertumbuhan juvenil Holothuria scabra menggunakan keramba apung dengan (ADR) dan tanpa (ATR) rumput lautdan keramba tancap dengan (TDR) dan tanpa (TTR) rumput laut di tambak.

Figure 2. Growth of Holothuria scabra juveniles reared in floating hapa with (ADR) and without

(ATR)seaweed, and fixed hapa with (TDR) and without (TTR) seaweed in earthen pond.

Hasil penelitian menunjukkan bahwa perlakuan ATR menghasilkan sintasan yang paling tinggi sebesar 98\%. Sintasan perlakuan tersebut tidak berbeda nyata dengan perlakuan
ADR namun berbeda nyata dengan perlakuan TTR dan TDR. Perlakuan TDR menghasilkan sintasan paling rendah yaitu sebesar 50\% (Gambar $3)$. 
Oseanologi dan Limnologi di Indonesia 2020 5(3): 199-208

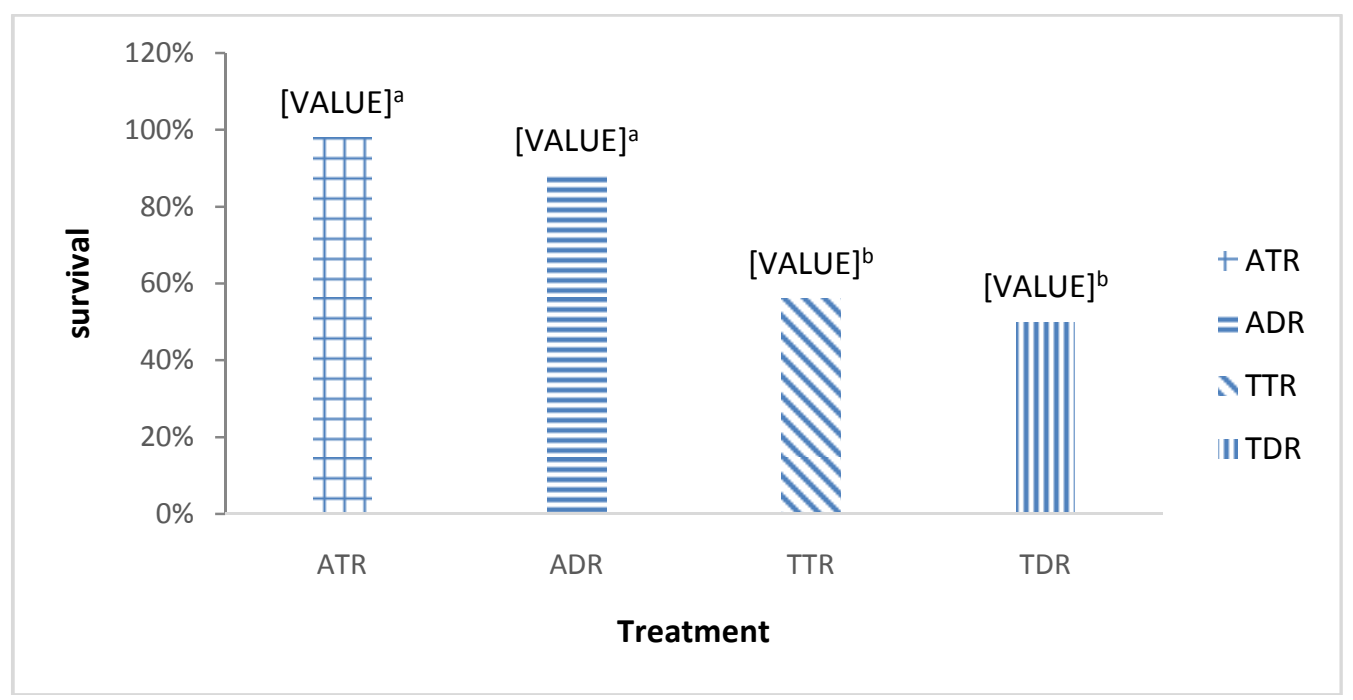

Gambar 3. Sintasan juvenil teripang Holothuria scabra menggunakan keramba apung dengan (ADR) dantanpa (ATR) rumput laut dan keramba tancap dengan (TDR) dan tanpa (TTR) rumput laut di tambak.

Figure 3. Survival Rate Growth of Holothuria scabra juveniles reared in floating hapa with (ADR) and without (ATR)seaweed, and fixed hapa with (TDR) and without (TTR) seaweed in earthen pond.

Parameter biomassa menunjukkan adanya beda nyata antar perlakuan $(\mathrm{P}<0,05)$. Biomassa terendah terdapat pada perlakuan TDR senilai 243,86 $\pm 24,98$ gram sedangkan nilai tertinggi sebesar 878,62 $\pm 103,27$ gram dicapai perlakuan ATR. Perlakuan TDR memiliki

biomassa yang berbeda nyata dengan semua perlakuan. Begitu juga dengan perlakuan ATR berbeda nyata dengan semua perlakuan. Perlakuan TTR memiliki biomassa yang tidak berbeda nyata dengan perlakuan ADR.

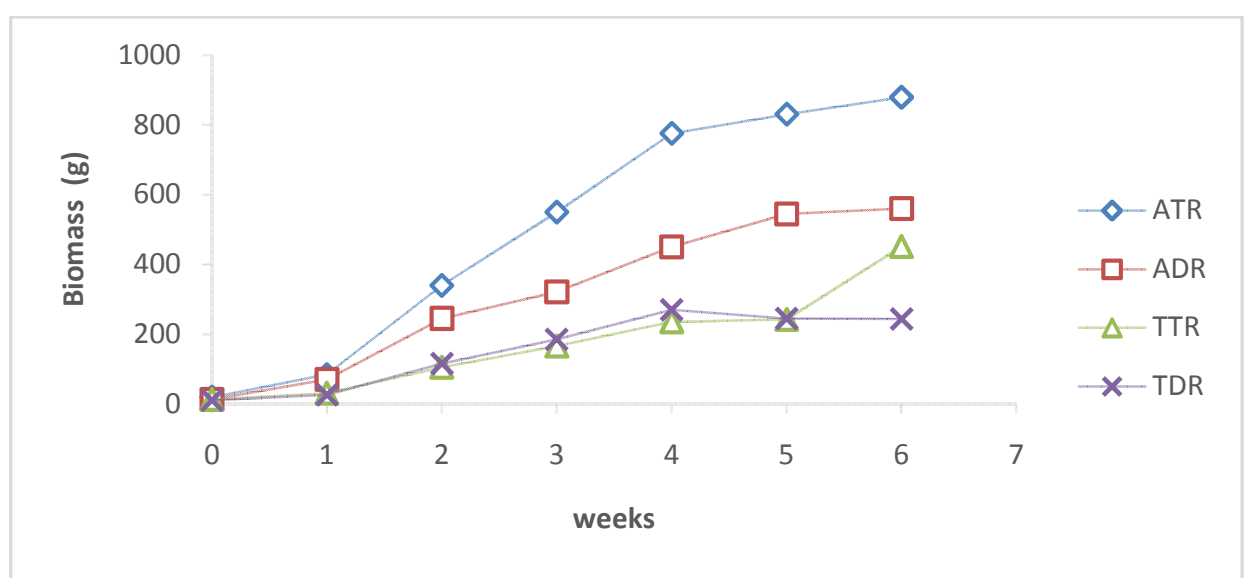

Gambar 4. Biomassa juvenil Holothuria scabra.

Figure 4. Biomass of Holothuria scabra juveniles.

Nilai biomassa berbanding lurus dengan sintasan dan rerata pertambahan berat. Perlakuan ATR menghasilkan biomassa paling tinggi karena memiliki sintasan dan pertumbuhan berat tertinggi. Pola pertumbuhan menunjukkan bahwa semua perlakuan mengalami pertumbuhan yang cukup baik di awal pemeliharaan. Pertumbuhan mulai melandai pada minggu ke 8 bahkan pada perlakuan karamba jaring tancap dengan penambahan rumput laut memiliki pola menurun (Gambar 4). Pola pertumbuhan tersebut sesuai dengan penelitianyang dilaporkan sebelumnya (Firdaus \& Indriana, 2019).

Kualitas air tambak di lokasi pemeliharaan disajikan dalam Tabel 2. Rerata oksigen terlarut sebesar5,70 $\pm 0,12 \mathrm{ppm}$, suhu air berada dalam kisaran $27,3-27,9{ }^{\circ} \mathrm{C}$. Fluktuasi salinitas juga tidak menunjukkan perubahan signifikan. Rentang salinitas selama masa pemeliharaan berkisar 33-34,5 ppt, sedangkan rerata $\mathrm{pH}$ selama pemeliharaan yaitu 7,85 $\pm 0,32$. 
Tabel 2. Parameter Kualitas air selama pemeliharaan juvenil Holothuria scabra

Table 2. Water quality parameters on grow out of Holothuria scabra juveniles

\begin{tabular}{|c|c|}
\hline Parameters & $\begin{array}{c}\text { Water Quality } \\
\text { (Mean } \pm \text { standart deviation) } \\
\text { (Range) }\end{array}$ \\
\hline $\begin{array}{c}\text { Temperature } \\
\left({ }^{\circ} \mathrm{C}\right)\end{array}$ & $\begin{array}{c}27.46 \pm 0.25 \\
27.3-27.9\end{array}$ \\
\hline $\begin{array}{l}\text { Salinity } \\
\text { (ppt) }\end{array}$ & $\begin{array}{c}34.13 \pm 0.65 \\
33-34.5\end{array}$ \\
\hline $\mathrm{pH}$ & $\begin{array}{c}7.85 \pm 0.32 \\
7.3-8.1\end{array}$ \\
\hline $\begin{array}{l}\text { Disolved Oxygen } \\
\quad(\mathrm{ppm})\end{array}$ & $\begin{array}{c}5.70 \pm 0.12 \\
5.5-5.8\end{array}$ \\
\hline
\end{tabular}

\section{Pembahasan}

Pemeliharaan juvenil teripang dilakukan selama 4 bulan dalam keramba tancap dan keramba apung dengan dan tanpa penambahan rumput laut Gracilaria sp. di tambak.Pemeliharaan dilakukan tanpa pemberian pakan. Pakan berasal dari bahan organik dan pakan alami lainnya yang tumbuh di bekas tambak udang.Pemberian rumput laut Gracilaria sp. bertujuan untuk memberikan naungan pada juvenil teripang (Firdaus et al., 2016). Selain itu rumput laut jenis ini juga mendukung proses bioremediasi (Mawi et al., 2020)serta mampu mengurangi kandungan hara berlebih seperti Nitrogen dan Fosfor yang terdapat dalam sistem budidaya (Panucci et al., 2009; Wei et al., 2017).

Secara umum kualitas air selama penelitian berada dalam rentang optimum untuk pertumbuhan teripang pasir. Suhu air berkisar antara $27,3-27,9^{\circ} \mathrm{C}$. Salinitas dalam kisaran 33-34,5 ppt. pH berkisar antara 7,3-8,1 dan Oksigen terlarut berada dalam kisaran 5,5-5,8 ppm. Kisaran optimal kualitas perairan untuk pertumbuhan benih teripang tersebut sama dengan penelitian-penelitian yang pernah dilakukan sebelumnya oleh Mills et al. (2012); Padang et al. (2016) dan Giri et al. (2019).

Beberapa penelitian melaporkan bahwa budidaya teripang pasir bersama Eucheuma denticulatum serta Kappaphycus striatum menghasilkan simbiosis mutualisme antar keduanya. Pertumbuhan rumput laut dapat meningkat dengan keberadaan teripang pasir sedangkan teripang pasir sendiri menghasilkan sintasan yang cukup tinggi dengan adanya rumput laut (Beltran-Gutierrez et al., 2016; Namukose et al., 2016). Hasil penelitian ini menunjukkan bahwa pemeliharaan juvenil teripang pasir bersama dengan rumput laut menyebabkan penurunan pada sintasan. Kematian juvenil teripang pasir terjadi sejak awal pemeliharaan pada semua perlakuan, namun pada keramba dengan penambahan rumput laut jumlahnya lebih tinggi. Hal tersebut diduga karena benih teripang pasir kurang menyukai rumput laut Gracilaria sp. yang memiliki permukaan yang licin sehingga benih teripang mengalami kesulitan saat menempel (Indriana \& Hilyana, 2014).

Nilai laju pertumbuhan pada penelitan ini berada pada kisaran $0,104-0,154$ gram per hari. Nilai tersebut masih dapat diterima bila dibandingkan dengan penelitian yang telah ada. Pemeliharaan teripang pasir pada fase juvenil awal menggunakan keramba di tambak telah dilakukan di Vietnam dengan laju pertumbuhan 0,02 gram per hari (Pitt \& Duy, 2004) dan 0,83 gram per hari (Duy, 2012). Hasil-hasil penelitian di Filippina, menunjukkan laju pertumbuhan sebesar 0,01 gram per hari and 0,052 gram per hari (Juinio-Menez et al., 2012, 2017). Di Kaledonia Baru, laju pertumbuhan yang dihasilkan sebesar 0,90 gram per hari (Agudo, 2012) dan 0,03 gram per hari (Purcell \& Agudo, 2013).

Rendahnya rerata pertambahan berat pada perlakuan dengan rumput laut Gracilaria sp. diduga disebabkan kompetisi unsur hara antara mikroalga dengan Gracilaria sp. yang terjadi dalam keramba yang dipakai (mikrohabitat). Kompetisi unsur hara tersebut diduga menyebabkan kelimpahan mikroalga di dalam karamba dengan rumput laut menjadi berkurang. Mikroalga yang termasuk diatom bentik merupakan makanan yang disukai teripang (Padang \& Lukman, 2014). 
Sintasan juvenil teripang pasir terutama pada fase pendederan yang dipelihara ditambak menunjukkan hasil yang bervariasi. Di Vietnam, sintasan sebesar $56 \%$ selama 41 hari pemeliharaan (Pitt \& Duy, 2004) dan 80\% selama 420 hari pemeliharaan (Duy, 2012). Lebih lanjut, penelitian Juinio-Menez et al. $(2012$, 2017) di Filipina memberikan hasil sintasan sebesar 57\% dan $80 \%$ masing-masing untuk masa pemeliharaan 30 dan 162 hari. Di Kaledonia Baru, nilai sintasan sebesar 69\% selama 360 hari pemeliharaan (Agudo, 2012) dan 84\% selama 35 hari pemeliharaan (Purcell \& Agudo, 2013).

Pada keramba jaring tancap dengan atau tanpa rumput laut menghasilkan nilai sintasan sebesar $50 \%$ dan $56 \%$ sedangkan pada perlakuan karamba jaring apung dengan atau tanpa rumput laut menghasilkan sintasan diatas $88 \%$. Penelitian terdahulu yang dilakukankan di Pulau Unguja, Zanzibar, Tanzania menghasilkan pertumbuhan dan sintasan yang cukup tinggi (Beltran-Gutierrez et al, 2014; Namukose et al., 2016). Sintasan teripang pasir $H$. scabra yang dipelihara secara polikultur dengan rumput laut Eucheuma denticulatum sebesar $83 \%$ pada perlakuan kepadatan rendah dengan laju pertumbuhan sebesar 0,80 $\pm 0,3$ gram per hari (Namukose et al., 2016). Sementara itu laju pertumbuhan teripang pasir yang dipelihara bersama rumput laut Kappaphycus striatumadalah 1,6 gram per hari (Beltran-Gutierrez et al., 2014). Hasil penelitian Purcell et al. (2006) menunjukkanbahwa coculture H. scabra dengan udang Litopenaeus stylirostris (Stimpson) sangat memungkinkan dilakukan pada stadia juvenil awal dengan nilai sintasan $73-100 \%$ selama 3 minggu masa pemeliharaan. Penelitian teripang di Indonesia menunjukkan hasil sintasan yang bervariasi. Firdaus \& Indriana (2019) menyebutkan bahwa sintasan juvenil teripang yang dipelihara di keramba jaring apung sebesar $75,56 \%$ setelah 14 minggu pemeliharaan sedangkan penelitian Giri et al. (2019) menunjukkan hasil 96,5-98\% selama 150 hari masa pemeliharaan. Sintasan dalam keramba tancap berkisar antara 31,11\% selama 14 minggu pemeliharaan (Firdaus \& Indriana, 2019), sedang Padang et al. (2016) melaporkan nilai sintasan sebesar 92,68\% dalam 150 hari pemeliharaan. Rendahnya nilai sintasan pada pemeliharaan menggunakan keramba tancap dengan atau tanpa rumput laut pada penelitian ini diduga disebabkan adanya juvenil yang terperangkap diantara lipatan dinding keramba yang terekspos saat air surut. Disisi lain penggunaan keramba jaring apung memungkinkan keramba selalu terendam air walaupun kondisi surut (Firdaus \& Indriana, 2019).
Pemilihan tempat pemeliharaan yang tepat akan mempengaruhi keberhasilan budidaya teripang pasir. Penelitian ini memberikan gambaran pemeliharaan benih teripang dengan metode jaring apung menghasilkan pertumbuhan berat dan sintasan yang lebih tinggi dibandingkan dengan metode jaring tancap. Pemberian rumput laut yang diharapkan mampu meningkatkan pertumbuhan dan sintasan justru menyebabkan penurunan pertumbuhan dan sintasan. Penambahan rumput laut pada sistem budidaya terintegrasi teripang memerlukan pengkayaan nutrien agar kebutuhan hara untuk rumput laut terpenuhi (Felaco et al., 2020). Pola pertumbuhan benih teripang pasir menunjukkan perlu adanya penjarangan atau penambahan pakan setelah minggu ke- 8 karena pertumbuhan yang cenderung melandai atau stagnan.

\section{Kesimpulan}

Pemeliharaan juvenil teripang pasir dengan metode keramba apung tanpa rumput laut direkomendasikan karena menghasilkan pertumbuhan dan sintasan yang tinggi, penambahan rumput laut Gracilaria sp. menunjukkan pola penurunan pertumbuhan dan sintasan. Penjarangan teripang perlu dilakukan setelah pemeliharaan selama 8 minggu agar pertumbuhan teripang dapat optimal.

\section{Persantunan}

Penelitian ini didanai oleh DIPA Balai Bio Industri Laut Tahun 2014. Terima kasih kepada Dr Sigit AP Dwiono, Nurhalis Tarmin dan semua pihak yang telah membantu kelancaran penelitian ini.

\section{Kontribusi}

Dedy Kurnianto dan Lisa F Indriana sebagai kontributor utama. Abdul Wahab, Safriyadi Hafid dan Balkam F Badi sebagai kontributor anggota.

\section{Daftar Pustaka}

Agudo, N., (2012). Pond grow-out trials for sandfish (Holothuria scabra) in New Caledonia. In: Hair, C., Pickering, T., Mills, D. (Eds.), Asia-Pacific Tropical Sea Cucumber Aquaculture. Proceedings of an International Symposium held in Noumea, New Caldonia, 15-17 February, 2011. Australian Centre for International Agricultural Research, Canberra, pp. 104112. 
https://coastfish.spc.int/en/component/conte $\mathrm{nt} /$ article/380-aciar-spc-asia-pacific-

tropical-sea-cucumber-aquaculturesymposium.html

Beltran-Gutierrez, M., Ferse, S. C., Kunzmann, A., Stead, S. M., Msuya, F. E., Hoffmeister, T. S., \& Slater, M. J. (2016). Co-culture of sea cucumber Holothuria scabra and red seaweed Kappaphycus striatum. Aquaculture Research, 47(5), 1549-1559. https://doi.org/10.1111/are.12615

Dumalan, R. J. P., Bondoc, K. G. V., \& Juinio Meñez, M. A. (2019). Grow-out culture trial of sandfish Holothuria scabra in pens near a mariculture-impacted area. Aquaculture, 507(April), 481-492.

https://doi.org/10.1016/j.aquaculture.2019.0 4.045

Duy, N.D., (2012). Large-scale sandfish production from pond culture in Vietnam. In: Hair, C., Pickering, T., Mills, D. (Eds.), Asia-Pacific Tropical Sea Cucumber Aquaculture. Proceedings of an International Symposium held in Noumea, New Caledonia, 15-17 February, 2011. Australian Centre for International Agricultural Research, Canberra, pp. 34-39. https://coastfish.spc.int/en/component/conte nt/article/380-aciar-spc-asia-pacifictropical-sea-cucumber-aquaculturesymposium.html

Felaco, L., Olvera-Novoa, M. A., \& Robledo, D. (2020). Multitrophic integration of the tropical red seaweed Solieria filiformis with sea cucumbers and fish. Aquaculture, 527(2020). https://doi.org/10.1016/ j.aquaculture. 2020.735475

Firdaus, M., \& Indriana, L. F. (2019). Nursery Performance of Sandfish Holothuria scabra Juveniles in Tidal Earthen Pond Using Different Types of Cage. IOP Conference Series: Earth and Environmental Science, 370(1). https://doi.org/10.1088/ $1755-1315 / 370 / 1 / 012024$

Firdaus, M, Indriana, L. F., Dwiono, S. A. P., \& Munandar, H. (2016). Konsep dan Proses Alih Teknologi Budidaya Terpadu Teripang Pasir, Bandeng dan Rumput Laut. Seminar Nasional Technopreneurship Dan Alih Teknologi, (February 2017), 51-63.

Friedlander, M., Levy, I. (1995) Cultivation of Gracilaria in outdoor tanks and ponds. $J$ Appl Phycol 7, 315-324. https://doi.org/10.1007/BF00004005

Giri, I. N. A., Sembiring, S. B. M., Wibawa, G. S., \& Haryanti, H. (2019). Pertumbuhan Teripang Pasir Holothuria scabra Yang
Dipelihara Dalam Bak Dan Karamba Jaring Apung Di Tambak Dengan Aplikasi Beberapa Formulasi Pakan Buatan. Media Akuakultur, 14(1), 19. https://doi.org/ 10.15578/ma.14.1.2019.19-29

Hamel J.-F., Mercier A., Conand C., Purcell S., Toral-Granda T.G., \& Gamboa R. (2013). Holothuria scabra. The IUCN Red List of Threatened Species 2013: e.T180257A1606648. http://dx.doi.org/10.2305/IUCN.UK.20131.RLTS.T180257A1606648.en

Indriana, L. F., Afrianti, Y., Hilyana, S., \& Firdaus, M. F. (2017a). Preferensi Penempelan, Pertumbuhan, Dan Sintasan Larva Teripang Pasir, Holothuria scabra Pada Substrat Lamun Yang Berbeda. Jurnal Riset Akuakultur, 11(3), 249. https://doi.org/10.15578/jra.11.3.2016.249258

Indriana, L. F., Firdaus, M., Supono, \& Munandar, H. (2017b). Survival Rate And Growth Of Juvenile Sandfish (Holothuria scabra) In Various Rearing Conditions. Marine Research in Indonesia, 42(1), 11. https://doi.org/10.14203/mri.v41i2.156

Indriana, L. F., \& Hilyana, S. (2014). Penggunaan substrat lamun dan makroalga untuk penempelan larva teripang pasir Holothuria scabra. Jurnal Akuakultur Indonesia, 13(1), 68-72.http://ejournal-balitbang.kkp.go.id/ index.php/jra

Indriana, L. F.,\& Firdaus, M. (2020). Growth Performance Of Sea Cucumber Holothuria Scabra Juvenile In Different Initial Size Of Pond Culture In Lombok, Indonesia. Proceeding 3rd ISMFR. E3S Web Of Conferences 147.

Https://Doi.Org/10.1051/E3sconf/20201470 1003

Juinio-Menez, M.A., de Peralta, G., Dumalan, R.J., Edullantes, C.M., Catbagan, T., (2012). Ocean nursery systems for scaling up juvenile sandfish (Holothuria scabra) production: ensuring opportunities for small fishers. In: Hair, C., Pickering, T., Mills, D. (Eds.), Asia-Pacific Tropical Sea Cucumber Aquaculture. Proceedings of an International Sysmposium held in Noumea, New Caledonia, 15-17 February, 2011. Australian Centre for International Agricultural Research, Canberra, pp. 57-62. https://coastfish.spc.int/en/component/conte nt/article/380-aciar-spc-asia-pacifictropical-sea-cucumber-aquaculturesymposium.html 
Juinio-Meñez, M.A., Tech, E.D., Ticao, I.P., Gorospe, J.R.C.,Edullantes, C.M.A., Rioja, R.A.V. (2017). Adaptive and integrated culture production systems for the tropical sea cucumber Holothuria scabra. Fisheries Research 186:502-513. https://doi.org/ 10.1016/j.fishres.2016.07.017

Mawi, S., Krishnan, S., \& Fadhil, M. (2020). Environmental Technology \& Innovation Bioremediation potential of macroalgae Gracilaria edulis and Gracilaria changii co-cultured with shrimp wastewater in an outdoor water recirculation system. Environmental Technology \& Innovation, 17, 100571. https://doi.org/10.1016/j.eti.2019.100571

Mills, D.J., Duy,N.D.Q., Juinio-Meñez, M.A., Raison C.M. and Zarate, J.M. (2012). Overview of sea cucumber aquaculture and sea-ranching research in the South-East Asian region. In C. A. Hair, T. D. Pickering, \& D. J. Mills (Eds.), AsiaPacific tropical sea cucumber aquaculture. Proceedings of an International Sysmposium held in Noumea, New Caledonia, 15-17 February, 2011. Australian Centre for International Agricultural Research, Canberra, pp.92103. Canbera:

https://coastfish.spc.int/en/component/conte nt/article/380-aciar-spc-asia-pacifictropical-sea-cucumber-aquaculturesymposium.html

Namukose, M., Msuya, F. E., Ferse, S. C. A., Slater, M. J., \& Kunzmann, A. (2016). Growth performance of the sea cucumber Holothuria scabra and the seaweed Eucheuma denticulatum: integrated mariculture and effects on sediment organic characteristics. Aquaculture Environment Interactions, 8(2016), 179-189. https://doi.org/10.3354/aei00172

Nursid, M. (2014). Prospek Pengembangan Teripang Pasir (Holothuria scabra) Sebagai Sumber Senyawa Bioaktif Dan Pangan Fungsional. In K. Sugama, I. N. A. Giri, \& M. Zairi (Eds.), Aspek biologi dan budidaya teripang pasir, Holothuria scabra (pp. 128145). Jakarta: AMAFRAD Press Badan.

Padang, A., \& Lukman, E. (2014). Komposisi makanan dalam lambung teripang. Agrikan: Jurnalllmiah Agribisnis dan Perikanan, 2(7), 26-30.

https://ejournal.stipwunaraha.ac.id/index.ph p/AGRIKAN/article/view/80/73.

Padang, A., Lukman, E., Sangadji, M., \& Subiyanto, R. (2016). Pemeliharaan teripang pasir (Holothuria scabra) di kurungan tancap. Agrikan: Jurnal Ilmiah Agribisnis Dan Perikanan, 9(2), 11.

https://doi.org/10.29239/j.agrikan.9.2.11-18

Panucci, R. A., Carneiro, M. A. A., \& Pereira, D.

C. (2009). Bioresource Technology Evaluation of Gracilaria caudata $\mathrm{J}$. Agardh for bioremediation of nutrients from shrimp farming wastewater. Bioresource Technology, 100(24), 6192$6198 . \quad$ https://doi.org/10.1016/ j.biortech.2009.06.102

Pitt, R., Duy, N.D., (2004). Breeding and rearing of sea cucumber Holothuria scabra in Vietnam. In: Lovatelli, A., Conand, C., Purcell, S., Uthicke, S., Hamel, J.-F., Mercier, A. (Eds.), Advances in Sea cucumber Aquaculture and Management. FAO Fisheries Technical Paper, Rome, pp. 333-346. https://www.worldfishcenter.org/ content/breeding-and-rearing-seacucumber-holothuria-scabra-viet-nam-0

Purcell, S.W., Patrois, J., Fraisse, N. (2006). Experimental Evaluation Of Co-Culture Of Juvenile Sea Cucumbers, Holothuria Scabra (Jaeger), With Juvenile Blue Shrimp, Litopenaeus Stylirostris (Stimpson). Aquaculture Research 37(5):515-522. https://doi.org/10.1111/ j.1365-2109.2006.01458.x

Purcell, S.W., Hair, C.A., Mills, D.J. (2012). Sea Cucumber Culture, Farming And Sea Ranching In The Tropics: Progress, Problems And Opportunities. Aquaculture368-369:68-81

https://doi.org/10.1016/j.aquaculture.2012.0 8.053.

Purcell, S. W., \& Agudo, N. S. (2013). Optimisation of mesh enclosures for nursery rearing of juvenile sea cucumbers. PloS one, 8(5), e64103. https://doi.org/10.1371/journal.pone.00641 03

Purcell, S. (2012). Principles and science of stocking marine areas with sea cucumbers. In C. A. Hair, T. D. Pickering, \& D. J. Mills (Eds.), Asia-Pacific tropical sea cucumber aquaculture. Proceedings of an International Sysmposium held in Noumea, New Caledonia, 15-17 February, 2011. Australian Centre for International Agricultural Research, Canberra, pp. 92103. Canbera.

https://coastfish.spc.int/en/component/conte nt/article/380-aciar-spc-asia-pacifictropical-sea-cucumber-aquaculturesymposium.html 


\section{Kurnianto et al.}

Purcell, S.W.(2014). Value, Market Preferences and Trade of Beche-De-Mer from Pacific Island Sea cucumbers, PLOS ONE, 9(4). 18. https://doi.org/10.1371/ journal.pone. 0095075. PMID: 24736374; PMCID: PMC3988149.

Sembiring, S. B. M., Arfah, R., \& Sugama, K. (1996). Perkembangan dan Sintasan Larva Teripang Pasir (Holothuria scabra). Jurnal Penelitian Perikanan Indonesia, II(1), 7781.http://ejournal-

balitbang.kkp.go.id/index.php/jra/article/vie $\mathrm{w} / 2117$

Tolon, T., Emiroğlu, D., Günay, D., \& Hanc1, B. (2017). Effect of stocking density on growth performance of juvenile sea cucumber Holothuria tubulosa (Gmelin, 1788). Aquaculture Research, 48(8), 41244131.

https://doi.org/10.1111/are.13232.

Wei, Z., You, J., Wu, H., Yang, F., Long, L., Liu, Q., Huo, Y. (2017). Bioremediation using Gracilaria lemaneiformisto manage the nitrogen and phosphorous balance in an integrated multi-trophic aquaculture system in. Marine Pollution Bulletin, (December 2016), 1-7. https://doi.org/10.1016/ j.marpolbul.2017.04.034 